\title{
Variation in Anti-icing Power of Superhydrophobic Electrothermal Film under Different Temperatures and Wind Speeds
}

\author{
Shijie Xue, ${ }^{1}$ Yihua Liu, ${ }^{2}$ Yu Wang, ${ }^{1}$ Bing Xiao, ${ }^{1}$ Xiaoxin Shi, ${ }^{1}$ Jingchun Yao, ${ }^{1}$ Xianglian Lv, ${ }^{1}$ \\ Weizheng Yuan, ${ }^{1}$ and Yang He ${ }^{1}$ \\ ${ }^{1}$ Key Laboratory of Micro/Nano Systems for Aerospace, Ministry of Education and Shaanxi Key Provincial Laboratory of Micro and \\ Nano Electromechanical Systems, Northwestern Polytechnical University, Xi'an 710072, China \\ ${ }^{2}$ AVIC Guizhou Aircraft Corporation Ltd., An Shun 561000, China
}

Correspondence should be addressed to Yang He; heyang@nwpu.edu.cn

Received 18 June 2021; Accepted 31 December 2021; Published 3 February 2022

Academic Editor: Mohammad Tawfik

Copyright (c) 2022 Shijie Xue et al. This is an open access article distributed under the Creative Commons Attribution License, which permits unrestricted use, distribution, and reproduction in any medium, provided the original work is properly cited.

\begin{abstract}
Anti-icing with low-energy consumption has important research value for unmanned aerial vehicles. In this study, a superhydrophobic electrothermal film for anti-icing applications was designed and prepared, and power consumption experiments were conducted at different temperatures and wind speeds in an icing wind tunnel. The anti-icing power consumption of the superhydrophobic electrothermal film was lower than that of a traditional electrothermal film. As the temperature decreased or the wind speed increased, the anti-icing power consumption of the two types of electrothermal films increased. A heat flux model was used to analyse the experimental results. It can be concluded that the water collection rate per unit area $(W)$ and wetting coefficient $\left(\xi_{w}\right)$ are the main factors affecting the power consumption of the superhydrophobic electrothermal film. When the temperature decreased and the wind speed increased, the contact time and contact area between the droplet and the surface affected $W$ and $\xi_{w}$. Thus, this study is of considerable significance for the design of superhydrophobic electrothermal films for novel anti-icing applications in the future.
\end{abstract}

\section{Introduction}

Aircraft icing seriously endangers flight safety, particularly when ice accretions form on the wing surface [1]. Related studies have shown that airfoil lift is most sensitive to ice accretion on its leading edge. Icing can also increase the aircraft weight, load, and fuel consumption [2]. Once ice accretion is formed on important parts, such as the wing, tail, and nose of the aircraft, it will also change the centre of gravity and lift, affecting flight stability, changing the centre of the lift, and deteriorating handling performance [3]. Traditional aircraft anti-icing technologies mainly include pneumatic pipes, spraying anti-icing fluids, gas thermal heating, and electrothermal heating. Pneumatic deicing technology breaks the ice on the surface through expansion pipes, but it changes the aerodynamic shape of the aircraft and causes additional drag. Anti-icing fluids are mainly used for anti-icing for aircraft on the ground and can cause environmental pollution [4]. The gas thermal anti-icing method uses hot air to heat aircraft components to achieve an anti-icing effect. However, this reduces the efficiency of the engine to a certain extent [5]. The electrothermal anti-icing method converts electric energy into thermal energy to heat the aircraft skin or its components, thereby preventing ice formation. However, traditional electrothermal systems consume a large amount of energy [6-13]. In recent years, researchers have observed that superhydrophobic surfaces have good anti-icing properties. These surfaces can delay the icing time and considerably reduce the icing adhesion force [14-17]. However, several experimental studies observed that simply using superhydrophobic surfaces cannot prevent icing under harsh conditions. In summary, existing aircraft anti-icing 
technology still has certain limitations in adapting to complex flight conditions.

Owing to the advantages of existing technology and superhydrophobic surfaces, highly efficient and energysaving anti-icing technologies have attracted considerable attention. Fortin et al.'s research showed that a hydrophobic coating applied to the surface of an airfoil could reduce the condensation of supercooled water droplets on the surface of the body and reduce the energy consumed for electric heating and anti-icing [18]. Antonini et al. proved that the use of superhydrophobic materials with a low surface energy could change the surface wettability of the material to accelerate the shedding of liquid on the surface of the body [19]. Pauw and Dolatabadi conducted an ice wind tunnel test using a low-surface-energy superhydrophobic paint and electric heating. The test results showed that the superhydrophobic electric heating compound could reduce the energy consumed for anti-icing by approximately $50 \%$ and reduce the deicing time by approximately $75 \%$ [20]. Sun et al. fabricated a controllable carbon nanowire/polydimethylsiloxane biomimetic nanocomposite film with a superhydrophobic surface, which exhibits superhydrophobicity, icephobicity, and controllable electric deicing. It was observed that the initial nucleation time of a single water droplet is delayed by $353.3 \mathrm{~s}$ on the superhydrophobic surface relative to the hydrophilic surface [21]. Qu et al. prepared a strong hydrophobic polypyrrole (PPy) coating with excellent anti-icing performance. Under the same ice wind tunnel test conditions, the maximum icing weight of a strongly hydrophobic PPy coating blade was almost $0.10 \mathrm{~g}$, whereas that of an uncoated blade was 26.13g [22]. Sun et al.'s thesis proved that superhydrophobic surfaces prepared by both spraying and laser ablation methods could efficiently reduce the energy consumption of the electrothermal system, and the maximum reduction reached $76.7 \%$ when the temperature of the heating surface was lower than $15^{\circ} \mathrm{C}[23]$. The above studies have proved the application prospects of superhydrophobicity in anti-icing and have considerable significance for further studies. However, no studies on the variation of the anti-icing power of superhydrophobic electrothermal films under different temperatures and wind speeds have been conducted so far. The mechanism of the effect of the superhydrophobic layer on power consumption is still unclear.

This study mainly investigates the variation in the antiicing power of superhydrophobic electrothermal films under different temperatures and wind speeds. The design and preparation of a superhydrophobic electrothermal film are described. Ice wind tunnel experiments under several conditions are conducted, and the experimental results are analysed. The reasons for the reduction in the anti-icing power consumption of the superhydrophobic electrothermal film and the change in the power consumption under different wind speeds and temperatures are explained by the heat flux model and the impact characteristics of the droplets.

\section{Experiments}

2.1. Design and Fabrication of Superhydrophobic Electrothermal Films. The superhydrophobic electrothermal film was composed of a superhydrophobic layer and an electrothermal layer. A synergy of superhydrophobic and electrothermal effects can be achieved, which is expected to reduce the power consumption required for anti-icing considerably. The schematic of the design is illustrated in Figure 1.

The preparation of the electrothermal layer mainly utilises etching technology. The electrothermal layer can be processed according to the designed electrothermal-layer pattern. The preparation process for the electrothermal layer is illustrated in Figure 2(a).

The superhydrophobic layer is formed by first forming a microstructure on the polyimide (PI) layer through an etching process and then using the plasma coating technique to reduce the surface energy of the material to achieve a superhydrophobic property. The preparation process is shown in Figure 2(b).

The contact angle, rolling angle, thickness, and dimensions of the superhydrophobic electric heating film are listed in Table 1.

2.2. Ice Wind Tunnel Experimental Setup. The setup for the ice wind tunnel experiment is illustrated in Figure 3. It mainly includes an icing wind tunnel, an NC0012 aerofoil experimental model (film and temperature sensor), a DC power supply (Tektronix-PWS4000, Tektronix Inc., USA), a DAQ board (PS2016, Simai Kehua Technology Co., Ltd., Beijing, China), and a camera (D7000, Nikon Inc., Japan). The NC0012 aerofoil experimental model was installed in the icing wind tunnel test section. The DC power supply was used to provide power for heating. The DAQ board was used to measure the temperature of the film surface during operation. The camera was placed outside the observation window of the test section to capture and record the anti-icing process of the film.

\section{Results and Discussion}

3.1. Experiment Results. In this study, four typical icing meteorological conditions were selected, which were determined based on unmanned aerial vehicle flight conditions and FAR 25. An ordinary electrothermal film and the superhydrophobic electrothermal film were tested under the same conditions to compare their anti-icing performances. Two different temperatures and wind speeds were selected to analyse the influence of these factors on the anti-icing performance.

In the ice wind tunnel experiment, the electrothermal film was heated to a certain power. If no ice was formed on the surface of the film within $1 \mathrm{~min}$, it was considered that the electrothermal film could achieve anti-icing under power. Then, the heating power was gradually reduced until the critical threshold power for ice accumulated on the surface of the film was reached. The results of anti-icing Experiment 1 for the ordinary electrothermal film and 


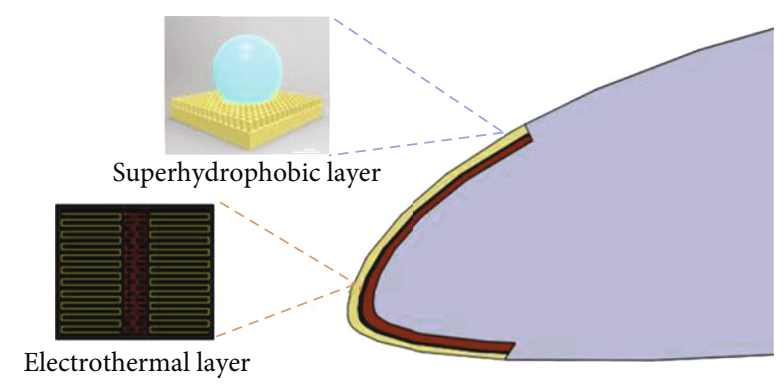

FIgURE 1: Schematic of design of the superhydrophobic electrothermal film.

superhydrophobic electrothermal film under the experimental conditions are shown in Figure 4. As shown in Figure 4(a), when the power was $19.8 \mathrm{~W}$, ice accumulated on the surface of the ordinary electrothermal film. As shown in Figure 4(b), when the power was $13.8 \mathrm{~W}$, ice accumulated on the leading edge of the superhydrophobic electrothermal film and formed a straight line. Therefore, the anti-icing thresholds of the ordinary electrothermal film and superhydrophobic electrothermal film were $19.8 \mathrm{~W}$ and $13.8 \mathrm{~W}$, respectively. Table 2 shows the parameters and results of ice wind tunnel Experiments 1-4.

3.2. Comparison of Anti-icing Power Consumption under Different Conditions. The anti-icing power consumption is measured based on the heat flux, which is the ratio of the anti-icing power to the area of the electric heating film. For instance, when the size of the designed electric heating film is $0.016 \mathrm{~m}^{2}$, the anti-icing thresholds of $13.75 \mathrm{~W}$ and $19.80 \mathrm{~W}$ correspond to heat fluxes of $859.38 \mathrm{~W} / \mathrm{m}^{2}$ and 1237.5 W/m ${ }^{2}$, respectively. As shown in Figure 5(a), under the aforementioned conditions, the heat flux of the superhydrophobic electrothermal film that can achieve anti-icing was lower than that of the ordinary electrothermal film. When the temperature decreased and the wind speed increased, the anti-icing heat flux of both the electrothermal films increased.

The superiority of the superhydrophobic electrothermal film over the ordinary electrothermal film is measured by their ability to reduce power consumption. For example, in Experiment 1, the ability of the superhydrophobic electrothermal film to reduce power consumption was $30.6 \%$ $((1237.5-859.4) / 1237.5)$. As shown in Figure 5(b), as the temperature decreased and the wind speed increased, the ability of the superhydrophobic electrothermal film to reduce power consumption compared with that of the ordinary electrothermal film decreased.

3.3. Reduction in Power Consumption. We used the heat flux model to explain the significant difference between the two types of films in terms of anti-icing power.

Figure 6 shows the heat flux on an ice surface. $q_{a}$ represents the heat flux owing to the convection heat transfer (W/ $\left.\mathrm{m}^{2}\right) \cdot q_{v}$ represents the heat flux $\left(\mathrm{W} / \mathrm{m}^{2}\right)$ of the surface caused by the friction of the boundary layer. $q_{e}$ represents the heat flux $\left(\mathrm{W} / \mathrm{m}^{2}\right)$ required for water evaporation (or ice sublimation) on the surface. $q_{w}$ represents the heat flux $\left(\mathrm{W} / \mathrm{m}^{2}\right)$ of water droplets collected by heating. $q_{w_{v}}$ represents the heat flux $\left(\mathrm{W} / \mathrm{m}^{2}\right)$ converted by the kinetic energy of water droplets. $q_{r}$ represents the radiant heat flux $\left(\mathrm{W} / \mathrm{m}^{2}\right)$ from the surface to the atmosphere of the anti-icing area. $q_{i}$ represents the melting heat $\left(\mathrm{W} / \mathrm{m}^{2}\right)$ released when the water droplets on the surface freeze.

When the anti-icing system is operating, the temperature of the wet surface is generally slightly higher than the freezing point of water; hence, $q_{r}$ can be ignored at this time. When the anti-icing system operates effectively, no icing occurs on the surface of the two types of electrothermal films; thus, $q_{i}$ can also be ignored. $q_{w_{v}}=W\left(V_{0}^{2} / 2\right), q_{w}=W$ $C_{W}\left(t_{s}-t_{0}\right)$, and the ratio of $q_{w}$ and $q_{w_{v}}$ is $\left(2 C_{W}\left(t_{s}-t_{0}\right) /\right.$ $\left.V_{0}^{2}\right)$. For instance, when $V_{0}=25(\mathrm{~m} / 2), t_{s}=0^{\circ} \mathrm{C}$, and $t_{0}=-$ $10^{\circ} \mathrm{C}$, the ratio is 133.984 . Compared with $q_{w}$, the value of $q_{w_{v}}$ is small; therefore, it can be ignored. Therefore, for the anti-icing surface, the required heating ratio $q_{n}$ can be approximately expressed as Equation (1). $q_{a}, q_{v}, q_{w}$, and $q_{e}$ are expressed in Equations (2)-(5) [24].

$$
\begin{aligned}
& q_{n}=q_{a}-q_{v}+q_{w}+q_{e}, \\
& q_{a}=\alpha\left(t_{s}-t_{l}\right),
\end{aligned}
$$

where $\alpha$ is the convective heat release coefficient $\left(\mathrm{W} / \mathrm{m}^{2} \cdot{ }^{\circ} \mathrm{C}\right)$ ; as the temperature decreases and wind speed increases, $\alpha$ increases; $t_{s}$ is the temperature of the anti-icing surface $\left({ }^{\circ} \mathrm{C}\right)$; and $t_{l}$ is the local temperature of the outer boundary of the boundary layer $\left({ }^{\circ} \mathrm{C}\right), t_{l}=t_{0}+\left(V_{0}^{2}-V_{l}^{2} / 2 C_{P}\right)=t_{0}+($ $\left.V_{0}^{2} \bar{p} / 2 C_{P}\right)$.

$$
q_{v}=\alpha\left(r^{*} \frac{V_{l}^{2}}{2 C_{P}}\right)
$$

where $V_{l}$ is the local velocity of the boundary layer $(\mathrm{m} / \mathrm{s})$, $V_{l}=V_{0} \sqrt{1-\bar{p}} ; \bar{p}$ is the pressure coefficient, which is greater than 0 and less than $1 ; r^{*}$ is the restoration coefficient of the boundary layer, which is approximately 0.72 ; and $C_{P}$ is the specific heat at constant pressure and its value is $1005 \mathrm{~J} / \mathrm{kg} \bullet{ }^{\circ} \mathrm{C}$.

$$
q_{w}=W C_{W}\left(t_{s}-t_{0}\right)
$$

where $C_{W}$ is the specific heat capacity of water; when $t=0^{\circ} \mathrm{C}$, $C_{W}=4187 \mathrm{~J} / \mathrm{kg} \bullet{ }^{\circ} \mathrm{C} ; W$ is the water collection rate per unit area $\left(\mathrm{kg} / \mathrm{m}^{2} \bullet \mathrm{s}\right)$; and $t_{0}$ is the atmospheric temperature $\left({ }^{\circ} \mathrm{C}\right)$.

$$
q_{e}=\xi_{w} W_{e v} L_{e}=1550 \alpha \xi_{w}\left(\frac{e_{s}}{p_{l}}-\frac{e_{0}}{p_{0}}\right),
$$

where $W_{e v}$ is the amount of water evaporated per unit area per unit time $\left(\mathrm{kg} / \mathrm{m}^{2} \bullet \mathrm{s}\right) ; L_{e}$ is the latent heat of water vaporisation; when $t=0^{\circ} \mathrm{C}, L_{e}=2500 \mathrm{~kJ} / \mathrm{kg}$; and $\xi_{w}$ is the wetting coefficient and is given by the ratio of the area covered by water to the total area. In the water impact zone, the value of $\xi_{w}$ is 1 ; if there is no water on the airfoil surface, the value of $\xi_{w}$ is $0 ; e_{s}$ is the corresponding saturated water vapour pressure at 


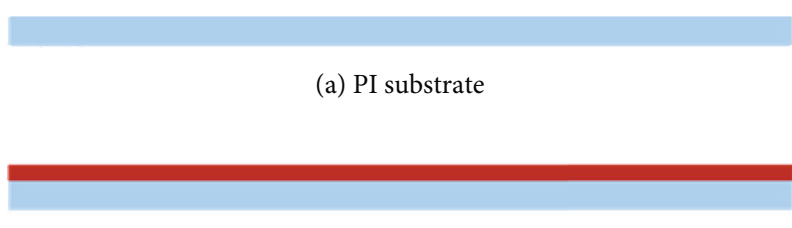

(b) Pasting the copper foil

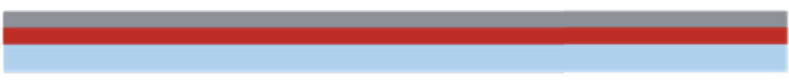

(c) Spinning photoresist

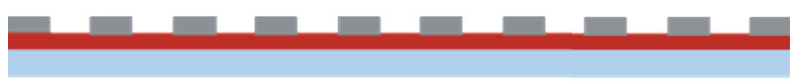

(d) Exposure and development

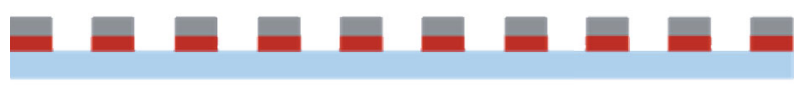

(e) Wet etching

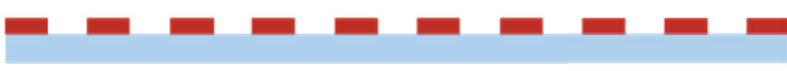

(f) Removing the photoresist

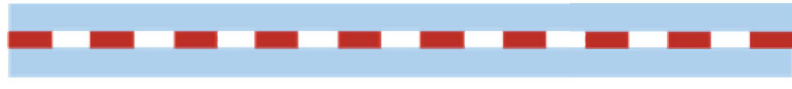

(g) Thermal compression bonding

(a) (a) PI substrate

(b) Sputtering an aluminium film

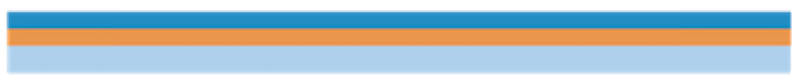

(c) Spinning photoresist

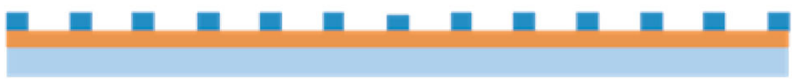

(d) Exposure and devlopment

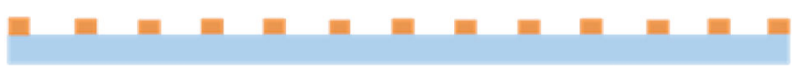

(e) Wet etching

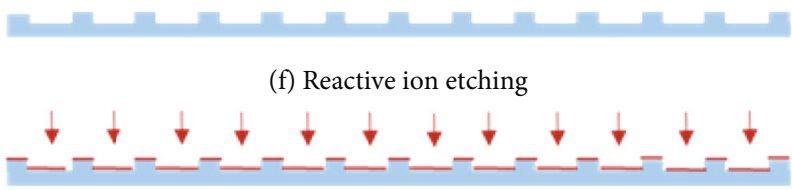

(g) Plasma surface treatment

(b)

Figure 2: Preparation process of the superhydrophobic electrothermal film. (a) Preparation process of the electrothermal layer. (b) Preparation process of the superhydrophobic layer.

TABle 1: Parameters of the superhydrophobic electrothermal film.

\begin{tabular}{lcccc}
\hline Parameter & $\begin{array}{c}\text { Contact } \\
\text { angle }\left({ }^{\circ}\right)\end{array}$ & $\begin{array}{c}\text { Roll-off } \\
\text { angle }\left({ }^{\circ}\right)\end{array}$ & $\begin{array}{c}\text { Thickness } \\
(\mu \mathrm{m})\end{array}$ & Size $(\mathrm{mm})$ \\
\hline Measurements & $152.5 \pm 1$ & $3.3 \pm 0.5$ & $300 \pm 50$ & $160 \times 100 \pm 1$ \\
\hline
\end{tabular}

temperature $t_{s}(\mathrm{~Pa}) ; e_{0}$ is the saturated water vapour pressure of the incoming flow $(\mathrm{Pa}) ; p_{l}$ is the local static pressure on the outer boundary of the boundary layer $(\mathrm{Pa})$; and $p_{0}$ is the air pressure of the incoming flow $(\mathrm{Pa})$.

Among the four heat fluxes, $q_{a}$ and $q_{v}$ of the superhydrophobic surface and the ordinary surface are approximately equal under the same conditions, whereas $q_{w}$ and $q_{e}$ are related to the impact of water droplets. For $q_{w}$ and $q_{e}$, the parameters $C_{W}, t_{s}, t_{0} \alpha, e_{s}, p_{l}$, and $p_{0}$ of the ordinary electrothermal film surface and the superhydrophobic electrothermal film surface are the same under the same experimental conditions; however, $W$ and $\xi_{w}$ are different. Thus, $q_{w}$ and $q_{e}$ decrease correspondingly as $W$ and $\xi_{w}$ of the superhydrophobic surface decrease, resulting in a lower anti-icing power.

An experiment was conducted to demonstrate the above mechanism. As shown in Supplementary Video 1, when the spray was started, there were evident water droplets on the surface of the electrothermal film and a water film was formed. As shown in Supplementary Video 2, when the spray was started, the water droplets flew off the surface of the superhydrophobic electrothermal film owing to the coupled force of surface tension and airflow shear stress; hence, no water film was formed. Therefore, under the same test conditions, the values of $W$ and $\xi_{w}$ on the surface of the superhydrophobic electrothermal film were lower.

In summary, the superhydrophobic surface has a lower $W$ and $\xi_{w}$ than the ordinary surface does. Therefore, $q_{w}$ and $q_{e}$ are lower, and thus, power consumption can be reduced with the superhydrophobic electrothermal film.

\subsection{Effect of Superhydrophobicity on Water Collection Rate} per Unit Area and Wetting Coefficient. A possible mechanism is proposed to explain the lower $W$ and $\xi_{w}$ of the superhydrophobic surface: the supercooled water has a shorter contact time on the superhydrophobic surface. When the supercooled water droplets impact the surface of the superhydrophobic electrothermal film, the droplets will have difficulty remaining in contact with the surface and will quickly fly off the airfoil under the action of aerodynamic force. 


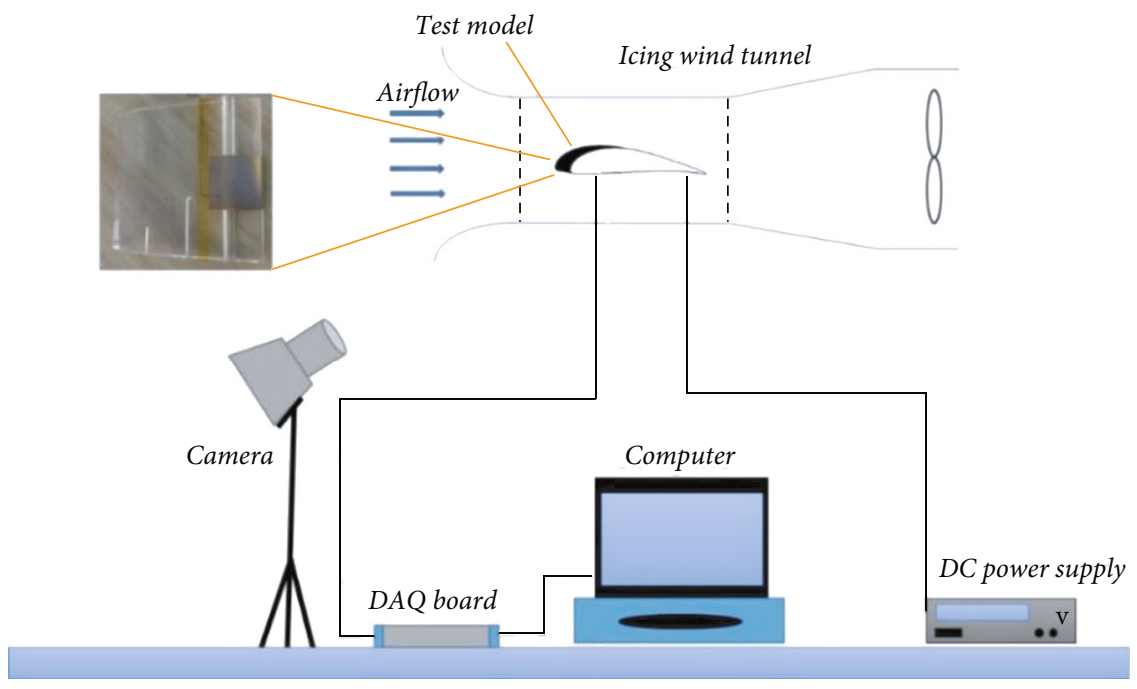

FIGURE 3: Setup for the anti-icing experiment.

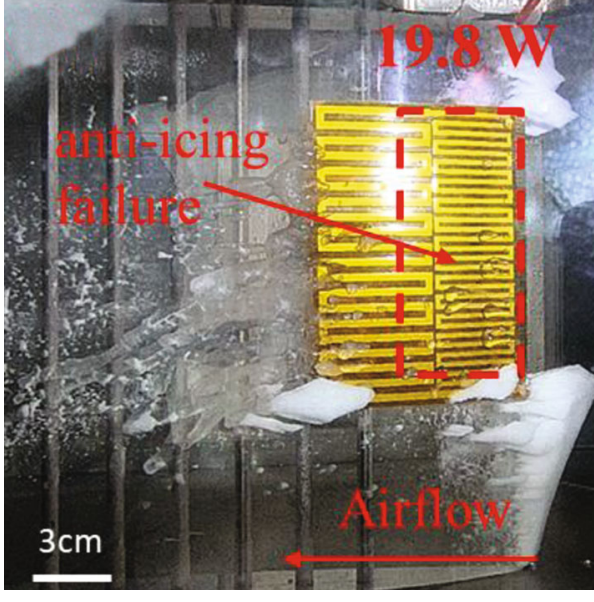

(a)

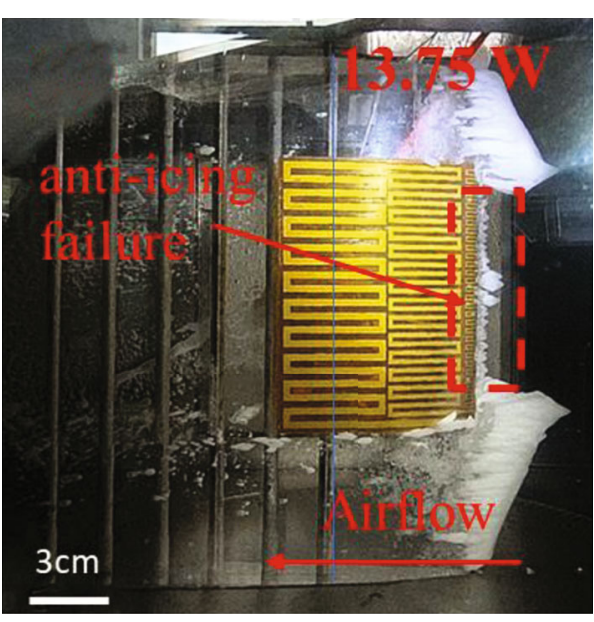

(b)

Figure 4: Anti-icing power thresholds of two types of electrothermal films. (a) Result of Experiment 1 for the ordinary electrothermal film (b) Result of Experiment 1 for the superhydrophobic electrothermal film.

TABLE 2: Parameters and results of the ice wind tunnel experiments.

\begin{tabular}{lcccccc}
\hline $\begin{array}{l}\text { Experiment } \\
\text { number }\end{array}$ & $\begin{array}{c}\text { Temperature } \\
\left({ }^{\circ} \mathrm{C}\right)\end{array}$ & $\begin{array}{c}\text { Wind } \\
\text { speed } \\
(\mathrm{m} / \mathrm{s})\end{array}$ & $\begin{array}{c}\text { LWC }(\mathrm{g} / \\
\left.\mathrm{m}^{3}\right)\end{array}$ & $\begin{array}{c}\text { MVD } \\
(\mu \mathrm{m})\end{array}$ & $\begin{array}{c}\text { Anti-icing power threshold of the } \\
\text { ordinary electrothermal film }(\mathrm{W})\end{array}$ & $\begin{array}{c}\text { Anti-icing power threshold of the } \\
\text { superhydrophobic electrothermal film } \\
(\mathrm{W})\end{array}$ \\
\hline 1 & $-10 \pm 0.5$ & $25 \pm 1$ & $0.644 \pm 0.05$ & 18.3 & 19.8 & 13.8 \\
2 & $-10 \pm 0.5$ & $40 \pm 1$ & $0.644 \pm 0.05$ & 18.3 & 44.5 & 35.2 \\
3 & $-15 \pm 0.5$ & $25 \pm 1$ & $0.644 \pm 0.05$ & 18.3 & 66 & 19.8 \\
4 & $-15 \pm 0.5$ & $40 \pm 1$ & $0.644 \pm 0.05$ & 18.3 & 54.5 \\
\hline
\end{tabular}

To prove this mechanism, we used a high-speed camera to observe the dynamic behaviour of water droplets on the superhydrophobic and hydrophilic surfaces. The droplet volume used in the experiment was $10 \mu \mathrm{L}$. As shown in Figure $7(\mathrm{a})$, droplets adhere to the hydrophilic surface, whereas, as shown in Figure $7(\mathrm{~b})$, droplets impacting the superhydrophobic surface rebounded within $3.12 \mathrm{~s}$. This remarkable property is due to a surface structure that favours the entrainment of air cushions beneath the drop, leading to the so-called Cassie state [25]. The actual situation is much more complicated and depends on the Cassie-Wenzel transitions, when a droplet is bouncing superhydrophobic surface 


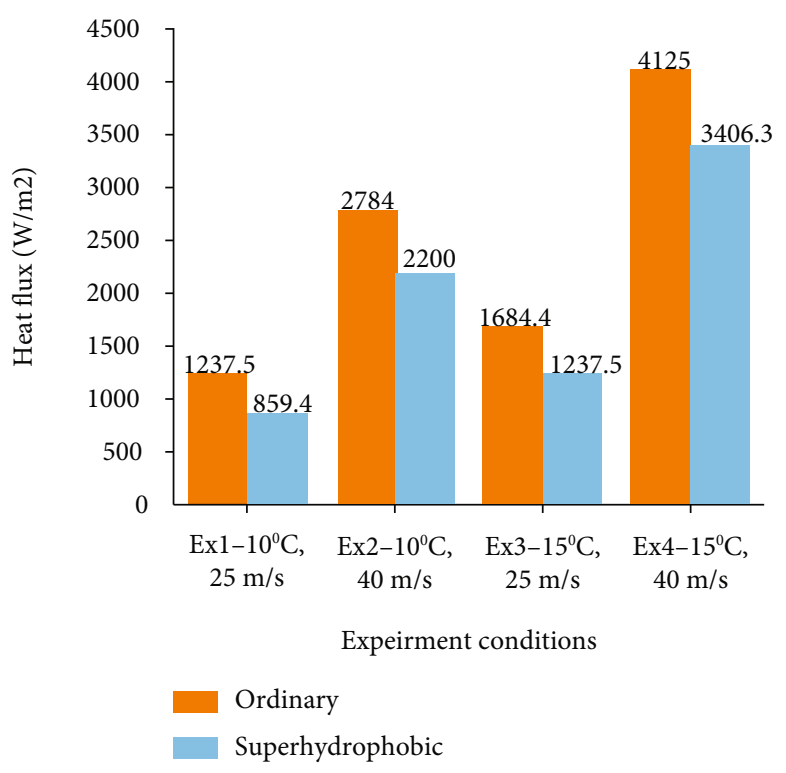

(a)

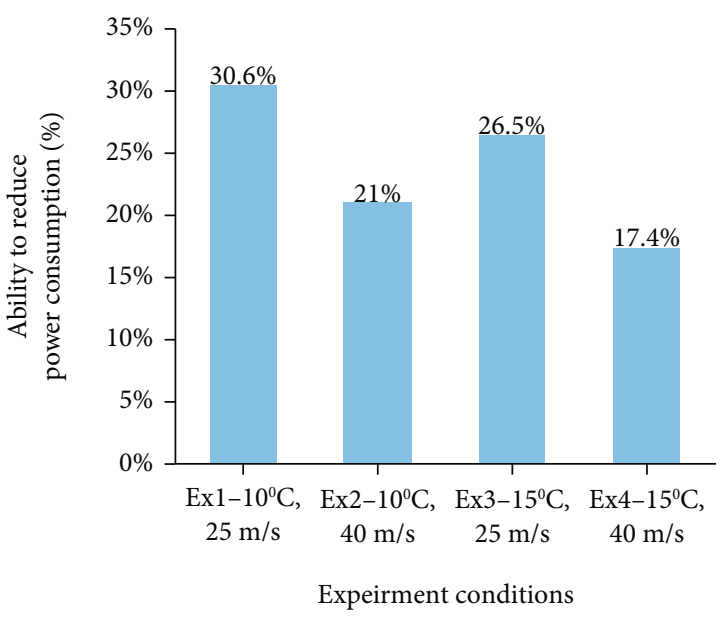

(b)

Figure 5: Experiment data analysis. (a) Comparison of power consumption between the superhydrophobic electrothermal film and the ordinary electrothermal film (b) Influence of temperature and speed on the reduction in power consumption.

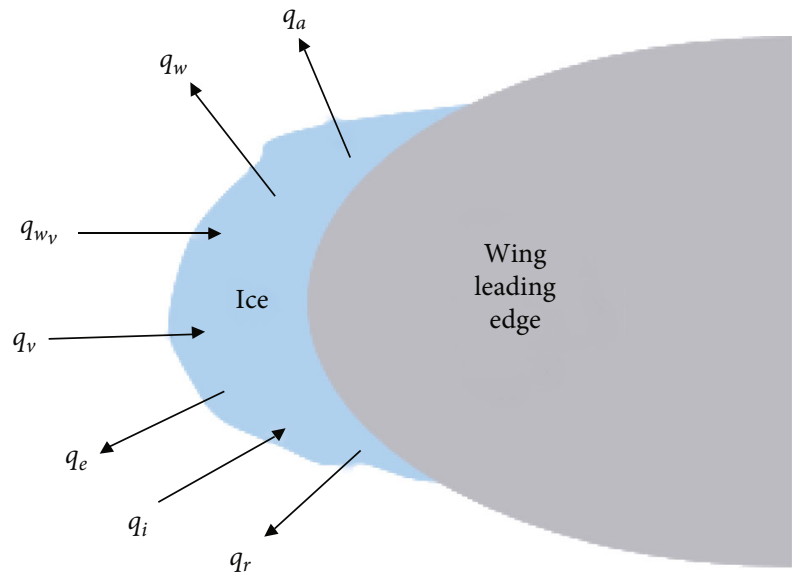

Figure 6: Heat flux on an ice surface.

[26]. Thus, the droplets remained for a shorter time on the superhydrophobic surface than on the hydrophilic surface.

Thus, the contact time of droplets may be the most important factor distinguishing between a superhydrophobic surface and an ordinary surface. Owing to the shorter contact time in the ice wind tunnel experiment, the droplets are more likely to leave the superhydrophobic surface. This leads to a lower $W$ and $\xi_{w}$ for the superhydrophobic surface.

\subsection{Changes in Anti-icing Power Consumption Owing to} Temperature and Wind Speed Changes. According to the experimental results, when the temperature decreased and the wind speed increased, the anti-icing power density increased. This phenomenon can also be explained by the heat flux model.

Changes in the temperature and wind speed affect the heat transfer on the airfoil surface. When the temperature decreases, $\alpha, t_{l}$, and $t_{0}$ increase. When the wind speed increases, $\alpha$ and $V_{l}$ increase. As shown in Equations (2)-(5), $q_{a}, q_{v}, q_{w}$, and $q_{e}$ increase as $\alpha, t_{l}$, and $t_{0}$ increase. Changes in the wind speed affect the behaviour of the supercooled water. When the wind speed is higher, more droplets will impact the airfoil surface per unit time and the wetting area of the airfoil surface is larger; therefore, $W$ and $\xi_{w}$ increase with the increase in wind speed. As shown in Equations (4) and (5), $q_{w}$ and $q_{e}$ increase with the increase in $W$ and $\xi_{w}$. As shown in Equation (1), $q_{n}=q_{a}-q_{v}+q_{w}+q_{e}$. The ratio of $q_{a}$ and $q_{v}$ given by $\left(2 C_{p}\left(t_{s}-t_{0}-\left(V_{0}^{2} \bar{p} / 2 C_{P}\right)\right)\right)$ $/\left(r^{*} V_{0}^{2}(1-\bar{p})\right)$ is greater than 1 (for instance, for $V_{0}=40$ $\mathrm{m} / \mathrm{s}, t_{s}=0^{\circ} \mathrm{C}$, and $t_{0}=-10^{\circ} \mathrm{C}$, the ratio is greater than 15 ); therefore, $q_{a}-q_{v}$ is greater than 0 .

Thus, as the temperature decreases and the wind speed increases, $q_{n}$ increases; thus, the power consumption of anti-icing increases, which is consistent with the experimental results.

3.6. Change in Impact Characteristics of Droplets with Temperature and Velocity. Thus, when the temperature decreases and the wind speed increases, in terms of the influence of the water impact on the macroscopic performance, $W$ and $\xi_{w}$ increase. However, the influence of the temperature and wind speed on the droplet impact characteristics at a microscopic level needs to be known. A possible mechanism is that, when the wind speed increases and the temperature decreases, the supercooled water has a longer contact time and larger contact area on the surface.

The temperature affects the contact time of the droplet with the surface. The supercooled liquid viscosity $(\mu)$ is related to the temperature (T), as shown in Equation (6) [27].

$$
\mu \propto(T-\mathrm{To})^{-\beta}
$$



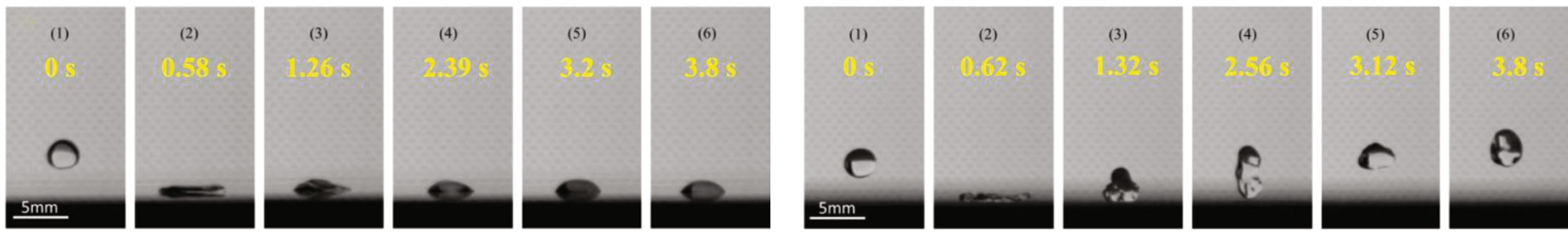

(a)

(b)

Figure 7: Dynamic behaviour of water droplets on two kinds of surfaces. (a) Ordinary electrothermal film surfaces. (b) Superhydrophobic electrothermal film surfaces.

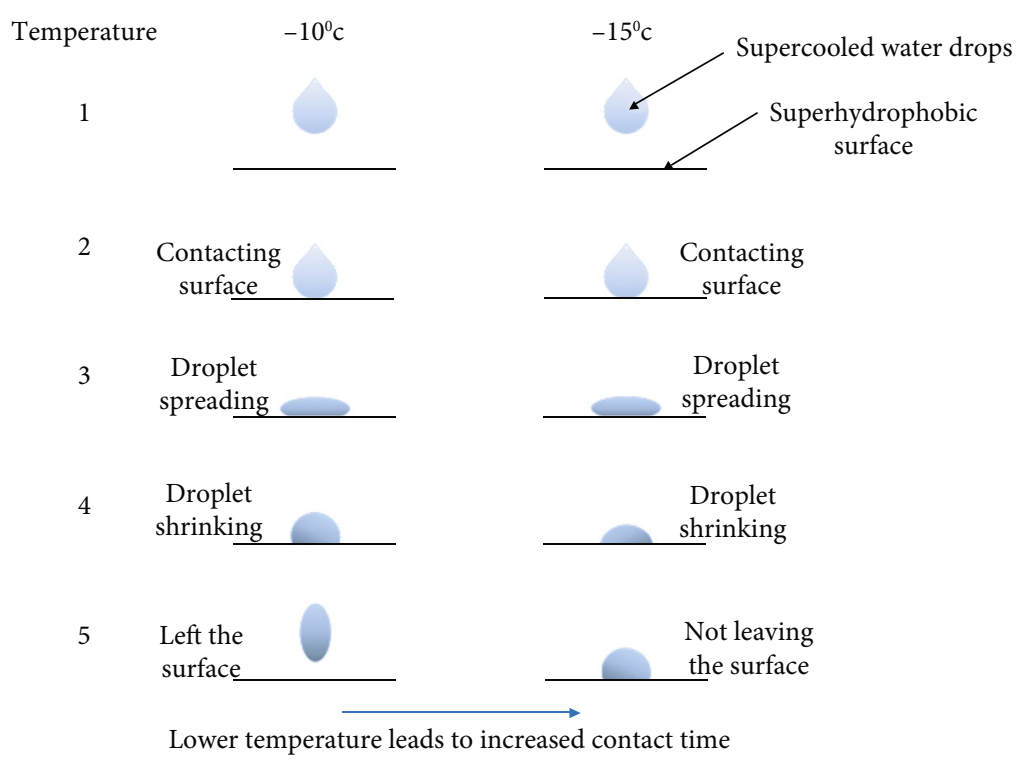

FIGURE 8: Effect of temperature change on the contact time of droplet bounce.

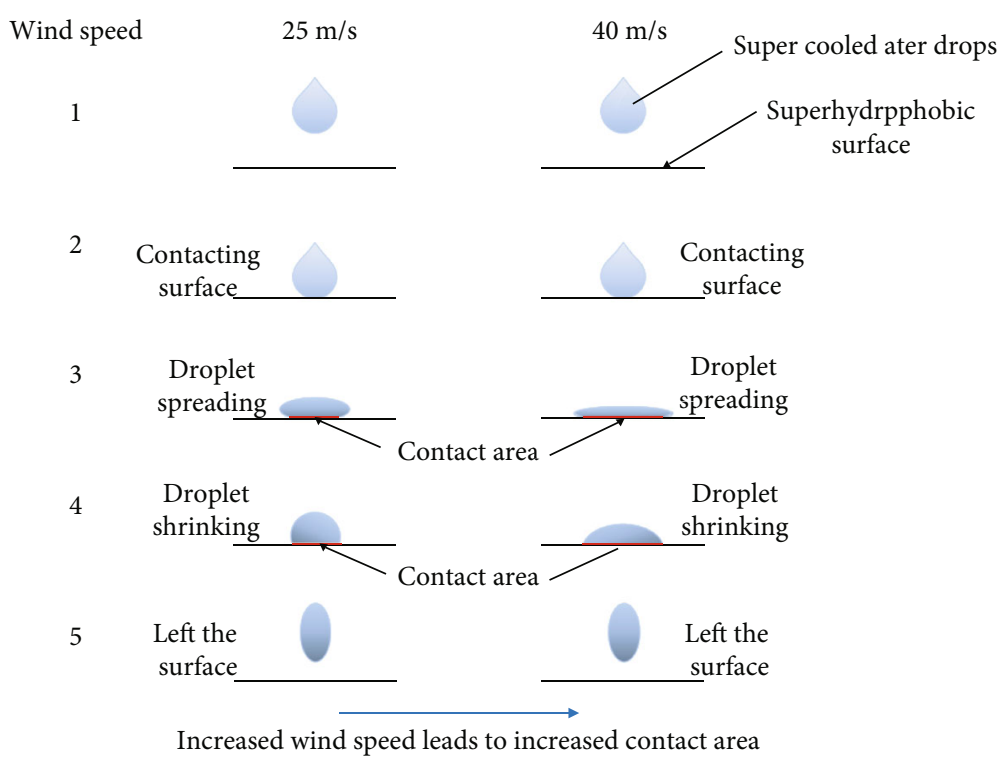

Figure 9: Effect of wind speed change on the contact area of droplet bounce. 
where To is the reference temperature and $\beta=1.64$ for water. That is, a decrease in temperature will cause the viscosity to increase rapidly. As shown in Figure 8, owing to the increase in viscosity, the bounce performance of water droplets decreases, and the contact time with the surface increases.

The wind speed affects the contact area between the droplet and the surface. The maximum expansion scale $\left(D_{\max }\right)$ of a superhydrophobic surface can be analysed using

$$
\frac{D_{\max }}{D_{0} \propto W_{e}^{0.25}},
$$

where $D_{0}$ is the droplet diameter and $W_{e}$ is the Weber number given by $W_{e}=\rho v^{2} l / \sigma$ [27], where $\rho$ is the fluid density, $v$ is the characteristic flow velocity, $l$ is the characteristic length, and $\sigma$ is the surface tension coefficient of the fluid. Therefore, as shown in Figure 9, when the wind speed increases, $W_{e}$ will increase according to Equation of $W_{e}$. From Equation (7), $D_{\max }$ will increase as $W_{e}$ becomes larger. That is, the contact area between the water droplets and the superhydrophobic electrothermal film increases. The greater the contact area of the supercooled water droplets, the greater is the probability of icing and the easier it is for ice nucleation to occur.

When the supercooled water droplets impact the surface of the airfoil at a higher speed, they have a larger spread area and are more likely to freeze. At lower temperatures, the viscosity of the supercooled water droplets on the surface increases, prolonging the time it takes for them to leave the surface. The increase in contact area and contact time will increase the $W$ and $\xi_{w}$ of the airfoil surface, thereby affecting $q_{w}$ and $q_{e}$.

\section{Conclusions}

A superhydrophobic electrothermal film based on a PI layer was designed and prepared, and the measured contact angle was $152.5^{\circ} \pm 1^{\circ}$. An anti-icing test was conducted in an icewind tunnel. The power consumption analysis showed that the anti-icing power of the superhydrophobic electrothermal film was $10.8 \%-30.6 \%$ lower than that of the ordinary electrothermal film under different experimental conditions. A decrease in temperature and an increase in wind speed will increase the anti-icing power consumption of the two electric heating films. Combining the heat flux model and the test results, the reasons for the reduction in power consumption by superhydrophilicity and the power consumption of anti-icing under different test conditions were explained. Furthermore, the effects of temperature and wind speed on the droplet impact characteristics were analysed.

Through the above investigations, the following conclusions can be drawn:

(1) Lower $W$ and $\xi_{w}$ are the main reasons for the lower anti-icing power consumption of superhydrophobic surfaces than that of ordinary electric heating surfaces
(2) The droplet can leave quickly after impacting the superhydrophobic surface; that is, the contact time is short, which is the main reason for the lower $W$ and $\xi_{w}$ of the superhydrophobic surface

(3) The reduction in temperature and the increase in wind speed can significantly increase the anti-icing power consumption of the two electric heating films, and the heat transfer and changes in $W$ and $\xi_{w}$ are the main factors affecting their power consumption

(4) As the temperature decreases, the viscosity of the water droplets increases, resulting in an increase in the contact time between the water droplets and the surface. As the wind speed increases, the Weber number increases, resulting in an increase in the contact area between the water droplet and the surface. Thus, $W$ and $\xi_{w}$ increase, ultimately affecting $q_{w}$ and $q_{e}$

This study has considerable significance for the design of new superhydrophobic electrothermal films for anti-icing applications in the future.

\section{Data Availability}

The ice wind tunnel experimental data used to support the findings of this study are available from the corresponding author upon request.

\section{Conflicts of Interest}

The authors declare that there is no conflict of interest regarding the publication of this paper.

\section{Acknowledgments}

The research work is supported by the National Natural Science Foundation of China (Grant Nos. 51875478, 51735011, and 52111530127); National Basic Research Project (JCKY2018); Aeronautical Science Foundation of China (2017ZC53036); and Science and Technology Foundation of State Key Laboratory (6142201200403).

\section{Supplementary Materials}

In this section, the ice wind tunnel test process of ordinary electrothermal film and superhydrophobic electrothermal film is provided; see videos 1 and 2 in the supplementary material. (Supplementary Materials)

\section{References}

[1] Y. Cao, W. Tan, and Z. Wu, "Aircraft icing: an ongoing threat to aviation safety," Aerospace Science and Technology, vol. 75, pp. 353-385, 2018.

[2] J. Palacios, E. Smith, J. Rose, and R. Royer, "Instantaneous deicing of freezer ice via ultrasonic actuation," AIAA Journal, vol. 49, no. 6, pp. 1158-1167, 2012.

[3] A. Lampton and J. Valasek, "Prediction of icing effects on the lateral/directional stability and control of light airplanes," 
Aerospace Science and Technology, vol. 23, no. 1, pp. 305-311, 2012.

[4] A. P. Broeren, S. Lee, and C. Clark, "Aerodynamic effects of anti-icing fluids on a thin high-performance wing section," Journal of Aircraft, vol. 53, no. 2, pp. 451-462, 2016.

[5] L. Ding, S. Chang, S. Yang, and M. Leng, "Study on heating strategies of nose cone electrothermal anti-icing," Journal of Aircraft, vol. 55, no. 3, pp. 1311-1316, 2018.

[6] H. J. Coffman, "Helicopter rotor icing protection methods," Journal of the American Helicopter Society, vol. 32, no. 2, pp. 34-39, 1987.

[7] S. Venna, Y. J. Lin, and G. Botura, "Piezoelectric transducer actuated leading edge de-icing with simultaneous shear and impulse forces," Journal of Aircraft, vol. 44, no. 2, pp. 509515, 2007.

[8] C. A. Martin and J. C. Putt, "Advanced pneumatic impulse ice protection system (Piip) for aircraft," Journal of Aircraft, vol. 29, no. 4, pp. 714-716, 1992.

[9] J. Palacios and E. Smith, "Dynamic analysis and experimental testing of thin-walled structures driven by shear tube actuators," in 46th AIAA/ASME/ASCE/AHS/ASC Structures, Structural Dynamics and Materials Conference, Austin, Texas, 2005.

[10] J. J. Reinmann, R. J. Shaw, and R. J. Ranaudo, "NASA's program on icing research and technology," in Proceedings of the symposium on flight in adverse environmental conditions, pp. 73-78, Kluwer Publishers, Norwell, MA, 1989.

[11] G. Zumwalt, "Icing tunnel tests of electro-impulse de-icing of an engine inlet and high-speed wings," in 23rd Aerospace Sciences Meeting, Reno, NV, USA, 2013.

[12] Z. Wang, Y. Xu, and Y. Gu, "A light lithium niobate transducer design and ultrasonic de-icing research for aircraft wing," Energy, vol. 87, pp. 173-181, 2015.

[13] T. Xie, J. Dong, H. Chen, Y. Jiang, and Y. Yao, "Experiment investigation on deicing characteristics and energy efficiency using infrared ray as heat source," Energy, vol. 116, pp. 9981005, 2016.

[14] S. Jung, M. Dorrestijn, D. Raps, A. Das, C. M. Megaridis, and D. Poulikakos, "Are superhydrophobic surfaces best for icephobicity?," Langmuir, vol. 27, no. 6, pp. 3059-3066, 2011.

[15] V. Hejazi, K. Sobolev, and M. Nosonovsky, "From superhydrophobicity to icephobicity: forces and interaction analysis," Scientific Reports, vol. 3, no. 1, p. 2194, 2013.

[16] A. Starostin, V. Strelnikov, V. Valtsifer, I. Lebedeva, I. Legchenkova, and E. Bormashenko, "Robust icephobic coating based on the spiky fluorinated $\mathrm{Al}_{2} \mathrm{O}_{3}$ particles," Scientific Reports, vol. 11, no. 1, article 84283, p. 5394, 2021.

[17] Z. Zhao, H. Chen, X. Liu, H. Liu, and D. Zhang, "Development of high-efficient synthetic electric heating coating for antiicing/de-icing," Surface and Coatings Technology, vol. 349, pp. 340-346, 2018.

[18] G. Fortin, M. Adomou, and J. Perron, "Experimental study of hybrid anti-icing systems combining thermoelectric and hydrophobic coatings," SAE International Journal of Aerospace, vol. 38, no. 3, pp. 281-283, 2011.

[19] C. Antonini, M. Innocenti, T. Horn, M. Marengo, and A. Amirfazli, "Understanding the effect of superhydrophobic coatings on energy reduction in anti-icing systems," Cold Regions Science and Technology, vol. 67, no. 1-2, pp. 58-67, 2011.
[20] D. de Pauw and A. Dolatabadi, "Effect of superhydrophobic coating on the anti-icing and deicing of an airfoil," Journal of Aircraft, vol. 54, no. 2, pp. 490-499, 2017.

[21] Y. Sun, X. Sui, Y. Wang, W. Liang, and F. Wang, "Passive antiicing and active electrothermal deicing system based on an ultraflexible carbon nanowire (CNW)/PDMS biomimetic nanocomposite with a superhydrophobic microcolumn surface," Langmuir, vol. 36, no. 48, pp. 14483-14494, 2020.

[22] B. Qu, Z. Sun, F. Feng, Y. Li, G. Tong, and R. Noor, "Preparation and anti-icing of hydrophobic polypyrrole coatings on wind turbine blade," International Journal of Rotating Machinery, vol. 2020, Article ID 8626457, 9 pages, 2020.

[23] H. Sun, G. Lin, H. Jin et al., "Experimental investigation of surface wettability induced anti-icing characteristics in an ice wind tunnel," Renewable Energy, vol. 179, pp. 1179-1190, 2021.

[24] B. L. Messinger, "Equilibrium temperature of an unheated icing surface as a function of air speed," Journal of the Aeronautical Sciences, vol. 20, no. 1, pp. 29-42, 1953.

[25] P. Papadopoulos, L. Mammen, X. Deng, D. Vollmer, and H. J. Butt, "How superhydrophobicity breaks down," Proceedings of the National Academy of Sciences, vol. 110, no. 9, pp. 3254$3258,2013$.

[26] J. Su, I. Legchenkova, C. Liu et al., "Faceted and circular droplet spreading on hierarchical superhydrophobic surfaces," Langmuir, vol. 36, no. 2, pp. 534-539, 2020.

[27] T. Maitra, C. Antonini, M. K. Tiwari et al., "Supercooled water drops impacting superhydrophobic textures," Langmuir, vol. 30, no. 36, pp. 10855-10861, 2014. 